\title{
The Supervenience Argument, Overdetermination, and Causal Drainage: Assessing Kim's Master Argument
}

\author{
Sven Walter \\ Institute of Cognitive Science \\ University of Osnabrueck \\ Albrechtstraße 28 \\ D-49069 Osnabrueck \\ s.walter@philosophy-online.de
}

For some fifty years now, nonreductive physicalism (NRP) has been the predominant position regarding the so-called "mind-body problem." According to NRP, all scientifically respectable entities are physical entities; entities which are not straightforwardly reducible to physical entities are at least physical in the broad sense that they are (asymmetrically) dependent upon physical entities. Mental (biological, chemical, geological etc.) properties or event-types, for instance, are, if not reducible to physical properties, at least supervenient upon or realized by them. ${ }^{\mathrm{i}}$ One reason for the popularity of NRP is the implausibility of competing theories, but its main boon is its promise to incorporate mentality into the physical realm everything else belongs to and so to respect the naturalistic attitude characteristic of our modern scientific age, while at the same time also preserving our self-conception as autonomous and freely deliberating agents. 
For decades, Jaegwon Kim has argued with incomparable vim and vigor that NRP unwittingly carries with it our mind's causal impotence, thereby destroying our very autonomy it was supposed to salvage. Kim's master

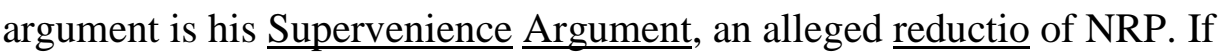
mental properties indeed supervene upon physical properties without being reducible to them, they are causally otiose (barring genuine overdetermination); since epiphenomenalism is absurd, mental properties must be reducible to physical properties. NRP is thus unable to steer a save path between the Scylla of reductionism on the one hand and the Charybdis of epiphenomenalism on the other, and should thus be abandoned in favor of reductive physicalism.

Judging by the amount of literature published by both friends and foes, Kim's Supervenience $\underline{\text { Argument }}$ is the by far most important argument against NRP. Kim formulated an early predecessor already in the late eighties under the label "Causal (or Explanatory) Exclusion $\underline{\text { Argument." The Supervenience }}$ Argument was first presented in an explicit form in Kim (1992a), and since then he has formulated it in various not always equivalent versions in the course of developing his own accounts of mental causation and psychophysical reductionism, which in turn have also been subject to enormous interest and criticism. In his latest book, Physicalism, Or Something Near Enough (Kim 2005), Kim returns to the fore, offering further defense of the Supervenience Argument and incorporating it into "a more clearly articulated overall view of the philosophical terrain involved" (Kim 2005, p. xi; see Walter 2008).

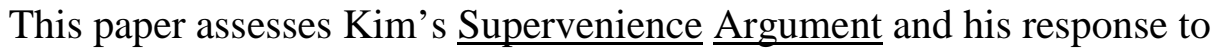


the two most important objections that have been raised against it. Along the way, Kim's position on several issues of the "philosophical terrain involved"causation, determination, the levels/orders distinction, or reduction, for instance-will be discussed. I argue that Kim does not provide a coherent overall picture of the mind and its place in the physical world. Pace Kim, the

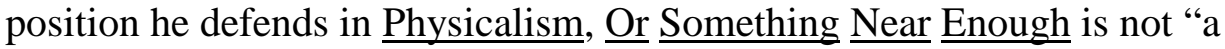
plausible terminus for the mind-body debate" (Kim 2005, p. 173).

Section 1 introduces and critically discusses the Supervenience Argument as it is presented in Kim (2005). Two objections have played a prominent role in recent discussions. First, several NRPs have argued that there is nothing objectionable about an event's being overdetermined by both a mental and a physical cause, in which case a central premise of the Supervenience Argument is false. Section 2 considers Kim's response to this "Overdetermination Argument" and finds it wanting. Second, several NRPs

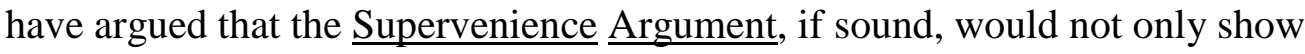
that there is no mental causation, but also that there is no biological, no chemical, no geological causation etc., a conclusion that, they argue, amounts to a reductio of the Supervenience Argument. Section 3 examines Kim's response to this "Generalization Argument," arguing that he does not succeed in spelling out a coherent overall position.

\section{The Supervenience $\underline{\text { Argument }}$}

The Supervenience Argument as presented in Kim (2005) has two stages. Stage 
one argues that mental properties can cause other mental properties only if they can cause physical properties. That is: Mental-to-mental causation is possible only if mental-to-physical causation is possible. Stage two argues that mental properties can cause physical properties only if they are reducible to physical properties or genuinely overdetermining. Since genuine overdetermination is not an option, mental-to-physical causation is possible only if mental properties are reducible to physical properties. Since the only remaining alternatives are therefore "reduction or causal impotence" (Kim 2005, p. 54), stages one and two together show that NRP is incompatible with mental causation, and since epiphenomenalism is absurd, reductive physicalism carries the day.

\subsection{The Supervenience Argument: $\underline{\text { Stage One }}$}

Consider an apparent instance of mental-to-mental causation, i.e., suppose that mental property $\underline{\mathrm{M}}$ causes mental property $\underline{\mathrm{M}}^{*}$. As Kim points out, "a shared minimum commitment of all positions that are properly called physicalist" (Kim 2005, p. 13), is that they accept the doctrine of mind-body supervenience:

$\underline{\text { Supervenience: }}$ Whenever an object $\underline{\mathrm{o}}$ has, at $\underline{\mathrm{t}}$, a mental property $\underline{\mathrm{M}}, \underline{\mathrm{o}}$ does so in virtue of the fact that $\underline{\mathrm{o}}$ has, at $\underline{\mathrm{t}}$, a physical property $\underline{\mathrm{P}}$, where $\underline{\mathrm{P}}$ (asymmetrically) necessitates $\underline{\mathrm{M}}{ }^{\mathrm{ii}}$

Given $\underline{\text { Supervenience, }}$, there must be a physical property $\underline{\mathrm{P}}^{*}$ which is noncausally sufficient for $\underline{\mathrm{M}}^{*}$ with at least nomological necessity. ${ }^{\mathrm{iii}}$ What is 
responsible for the occurrence of $\underline{\mathrm{M}}^{*}, \underline{\mathrm{M}}$ or $\underline{\mathrm{P}}^{*}$ ? There appears to be "a tension between vertical determination and horizontal causation” (Kim 2003, p. 153), i.e., between $\underline{P}^{*}$ 's claim to be $\underline{M}^{*}$ 's (non-causally sufficient) supervenience base on the one hand and $\underline{\mathrm{M}}$ 's claim to be $\underline{\mathrm{M}}^{*}$ 's cause on the other. Moreover, $\underline{\mathrm{P}}^{*}$ seems to preempt $\underline{\mathrm{M}}$ : Given $\underline{\text { Supervenience, }}$, as long as $\underline{\mathrm{P}}^{*}$ is there, $\underline{\mathrm{M}}^{*}$ will be there, no matter what happened before-even if $\underline{\mathrm{M}}^{*}$ 's alleged cause, $\underline{\mathrm{M}}$, had not been present:

$[\mathrm{U}]$ nder the assumption of mind-body supervenience, $\mathrm{M}^{*}$ occurs because its supervenience base $\mathrm{P}^{*}$ occurs, and as long as $\mathrm{P}^{*}$ occurs, $\mathrm{M}^{*}$ must occur ... regardless of whether or not an instance of $\mathrm{M}$ preceded it. This puts the claim of $\mathrm{M}$ to be a cause of $\mathrm{M}^{*}$ in jeopardy: $\mathrm{P}^{*}$ alone seems fully responsible for, and capable of accounting for, the occurrence of M*. (Kim 1998, p. 42)

The tension between $\underline{\mathrm{M}}$ and $\underline{\mathrm{P}}^{*}$ is not a causal tension: $\underline{\mathrm{M}}$ claims to be causally sufficient for $\underline{\mathrm{M}}^{*}$ while $\underline{\mathrm{P}}^{*}$ is non-causally sufficient for $\underline{\mathrm{M}}^{*}$. Why then, exactly, do $\underline{\mathrm{M}}$ and $\underline{\mathrm{P}}^{*}$ compete? For a while, Kim appealed to a general principle to justify the tension between $\underline{\mathrm{M}}$ and $\underline{\mathrm{P}}^{*}$ :

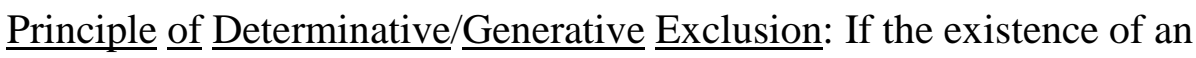
event $\mathrm{e}$, or an instantiation of a property $\mathrm{P}$, is determined/generated by an event c- causally or otherwise-then e's occurrence is not determined/generated by any event wholly distinct from or independent 
of c (unless this is a genuine case of overdetermination). (Kim 2001, p. 277; emphasis S.W.)

Later, however, Kim said he would "prefer not to appeal to any general 'principle' in support of [this tension; S.W.] ... I don't believe that the invocation of any general principle will help persuade anyone who is not with me here" (Kim 2003, p. 156n6). Given this, it is surprising that he spends several pages of Kim (2005) motivating a claim called "Edwards' dictum" as "[t]he idea that drives the supervenience argument" (Kim 2005, p. 36), where Edwards' dictum just appears to be a (much less precise) version of the Principle of Determinative/Generative Exclusion:

Edwards' dictum: There is a tension between 'vertical' determination and 'horizontal' causation. In fact, vertical determination excludes horizontal causation. (Kim 2005, p. 36)

Not only is Kim's vacillation puzzling, his invocation of Edwards' dictum and the prominent role he relegates to it in Kim (2005) are strange, too.

First, it should be noted that Edwards' dictum and the Principle of $\underline{\text { Determinative/Generative Exclusion are both stronger and intuitively much }}$ less plausible than a second, simpler principle called 'Exclusion' that Kim introduces elsewhere (Exclusion rules out two or more independent causes of any given event, but is silent on non-causal determinative factors; see below, section 1.2). Edwards' dictum alone, for instance, would suffice to establish 
stage one of the Supervenience Argument: NRPs accept that the way the micro-world is completely determines the way the macro-world is; hence, if vertical determination excluded horizontal causation, then autonomous higherlevel (mental-to-mental) causation would be possible only via the most fundamental micro-physical level. ${ }^{\text {iv }}$

Second, there is no need at all for Kim to appeal to Edwards' dictum in setting out stage one. ${ }^{v}$ Stage one is supposed to establish that the tension between $\underline{M}$ and $\underline{\mathrm{P}}^{*}$ can be resolved only by accepting that " $\underline{\mathrm{M}}$ caused $\underline{\mathrm{M}}^{*} \underline{\text { by }}$ causing its supervenience base $\underline{\mathrm{P}}^{*}$ " (Kim 2005, p. 40), and NRPs ought to accept this, no matter whether Edwards' dictum holds or not. Given Supervenience, the macro-world is the way it is because the micro-world is the way it is, and that means that changes at the macro-level can be brought about only via changes at the micro-level, so that the only way to cause a macroproperty is to cause its supervenience base (see Kim 1998, p. 42).

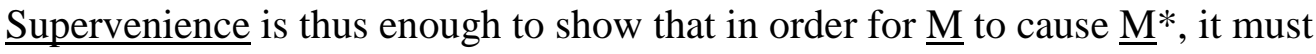
cause $\underline{\mathrm{M}}^{*}$ 's supervenience base $\underline{\mathrm{P}}^{*}$, and that concludes stage one: mental-tomental causation is possible only if mental-to-physical causation is possible.

\subsection{The Supervenience Argument: $\underline{\text { Stage Two }}$}

According to stage two of the Supervenience Argument, mental-to-physical causation is possible only if mental properties are reducible to physical properties.

NRPs typically accept a principle of causal closure according to which 
"there is no need to go outside the physical domain to find a cause ... of a physical event" (Kim 2005, p. 16):

Closure: If a physical event $\mathrm{p}$ has a sufficient cause at $\underline{\mathrm{t}}$, it has a sufficient completely physical cause at $\underline{\mathrm{t}}$.

NRPs of course also deny that mental properties are reducible to physical properties:

Irreducibility: Mental properties are not reducible to physical properties.

Stage one showed that $\underline{\mathrm{M}}$ can cause $\underline{\mathrm{M}}^{*}$ only by causing $\underline{\mathrm{P}}^{*}$. Given $\underline{\mathrm{Closure}}, \underline{\mathrm{P}}^{*}$ has also a sufficient completely physical cause $\underline{\mathrm{P}}$. But then, how can $\underline{\mathrm{M}}$ cause

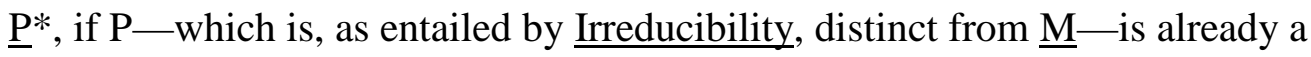
sufficient cause of $\underline{\mathrm{P}}^{*}$ ? This question is particularly pertinent in the light of Kim's principle of causal exclusion, according to which "[n]o single event can have more than one sufficient cause at any given time-unless it is a genuine case of causal overdetermination" (Kim 2005, p. 42):

Exclusion: Except for cases of genuine overdetermination, no event can have more than one sufficient cause at any given time.

Exclusion entails that there is a competition between $\underline{M}$ and $\underline{P}$ for the role of $\underline{\mathrm{P}}{ }^{*}$ 's cause, which, given $\underline{\mathrm{Closure}}, \underline{\mathrm{M}}$ is bound to loose (barring genuine 
overdetermination; see below). If $\underline{\mathrm{P}}$ is a sufficient cause of $\underline{\mathrm{P}}^{*}$, then once $\underline{\mathrm{P}}$ is instantiated, there is apparently nothing left for $\underline{\mathrm{M}}$ to contribute to the production of $\underline{\mathrm{P}}^{*}$, unless $\underline{\mathrm{M}}$ is identical to $\underline{\mathrm{P}}$ or $\underline{\mathrm{P}}^{*}$ is genuinely overdetermined.

Hence, mental-to-physical causation is possible only if either mental properties are reducible to physical properties (in which case Irreducibility is false and Exclusion is respected because there is only a single property) or cases of mental-to-physical causation are cases of genuine overdetermination (in which case Exclusion is respected because genuine overdetermination is explicitly exempted from it). Assuming that genuine overdetermination is not an option (see section 2), psychophysical reductions are thus the last bastion against epiphenomenalism, and this completes stage two. ${ }^{\text {vi }}$ The only remaining alternatives are "reduction or causal impotence" (Kim 2005, p. 54), but NRP is no longer a serious option.

Kim's Supervenience Argument strikes at the very heart of current philosophy of mind. If sound, it shows that one cannot escape epiphenomenalism if one accepts $\underline{\text { Supervenience, }} \underline{\text { Closure, }} \underline{\text { Irreducibility }}$ and Exclusion. ${ }^{\text {vii }}$ Drawing on just a few intuitively plausible and for the most part widely held principles, a straightforward line of reasoning seems to show that the currently most popular account of the mind entails its causal inefficacy. Since physicalists will not deny Supervenience, those unwilling to embrace epiphenomenalism and reluctant to accept Kim's reductionist conclusion are likely to focus on stage two. In particular, NRPs who will typically accept

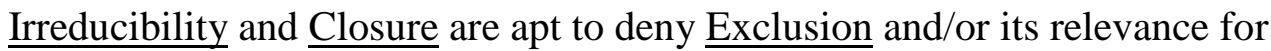
alleged cases of mental-to-physical causation. That is indeed what the two most 
influential objections against the Supervenience $\underline{\text { Argument, }}$, the

Overdetermination Argument and the Generalization Argument have done.

Kim has recently responded to these arguments, and in the remainder of this

paper, his response will be critically examined.

\section{The Overdetermination Argument}

Since genuine overdetermination is explicitly exempted from Exclusion, the line of reasoning sketched in the previous section does not establish that "any mental property ... that is causally efficacious must be a physical property or be reducible to physical properties" (Kim 2003, p. 152) unless the possibility of genuine overdetermination is ruled out. According to the Overdetermination Argument, this is the weak spot of the Supervenience Argument. There are two versions of this argument. One can either accept Exclusion, but deny its relevance for cases of mental-to-physical causation because they are understood as cases of genuine overdetermination, or one can treat mental-tophysical causation as a case of systematic, rather than genuine, overdetermination, in which case Exclusion is simply false because in cases of systematic overdetermination an event can have more than one sufficient cause at a given time, too (and not only in typical cases of genuine overdetermination, as Exclusion holds). Either way, the Supervenience Argument fails.

Treating mental-to-physical causation as a typical case of genuine overdetermination, as when a victim is shot simultaneously by two assassins or 
when a copper rod lengthens as a result of being both heated and subjected to a longitudinal stress simultaneously, is problematic for at least two reasons. First, such cases usually seem to contain a massive element of coincidence (see Kim 1998, p. 44) and, second, overdetermining causes are dispensable since each of them would suffice for the occurrence of the effect, while we want the mental to play an essential role in the causation of our behavior (see Kim 1998, p. 44 45). Apart from that, it just seems extremely odd to think that each and every bit of action we perform is overdetermined in virtue of having two distinct sufficient, but independent, causes (see Kim 1989b, p. 247). The appeal to genuine overdetermination does not appear to be a very promising strategy.

However, the kind of overdetermination NRPs typically have in mind is not like typical cases of genuine overdetermination at all, because the causes in question are not independent. First, the co-occurrence of the two causes is systematic and thus not coincidental, because Supervenience ensures that the presence of the physical cause necessitates the presence of the alleged mental cause. Second, neither of the co-occurring causes is dispensable in the same sense as, say, the two assassins' shots are dispensable as causes of the victim's death: Given $\underline{\text { Supervenience, }} \underline{\mathrm{M}}$ will be present as long as $\underline{\mathrm{P}}$ is present, so that dispensing with $\underline{\mathrm{M}}$ requires dispensing with $\underline{\mathrm{P}}$, in which case the effect might fail to occur and $\underline{\mathrm{M}}$ may not be dispensable after all (see Loewer 2001, p. 319).

What prevents NRPs from treating mental-to-physical causation as a case of systematic overdetermination?

\subsection{Overdetermination and $\underline{\text { Closure }}$}


In earlier writings, Kim argued that genuine overdetermination would conflict with Closure:

$[T]$ he overdetermination idea violates the causal closure principle ...: in the counterfactual situation in which the physical cause does not occur, the causal closure principle is violated. For the idea that the mental and the physical cause are each an independent sufficient cause involves the acceptance of the counterfactual that if the physical cause had not occurred, the mental cause would have occurred and caused the physical effect. (Kim 1989a, p. 281; see also Kim 1998, p. 45)

If $\underline{\mathrm{P}}^{*}$ were genuinely overdetermined by $\underline{\mathrm{M}}$ and $\underline{\mathrm{P}}, \mathrm{Kim}$ is suggesting, then in a possible world $\underline{\mathrm{W}}$ where $\underline{\mathrm{M}}$ occurs but neither $\underline{\mathrm{P}}$ nor any other physical cause $\underline{\mathrm{P}}^{\prime}$ of $\underline{P}^{*}$ occurs, $\underline{M}$ would still cause $\underline{P}^{*}$, thereby violating $\underline{\text { Closure }}$.

However, as Kim's opponents have pointed out, this is a non-sequitur as far as systematic overdetermination is concerned (see Crisp and Warfield 2001; Loewer 2001, 2002). Since Supervenience has modal force, one must venture (at least) beyond the nomologically possible worlds in order to find a world $\underline{\mathrm{W}}$ in which $\underline{\mathrm{M}}$ has no physical property that would occupy the role of the cause of $\underline{P^{*}}$ if $\underline{\mathrm{P}}$ failed to occur, and physicalists, it seems, should not be bothered by the

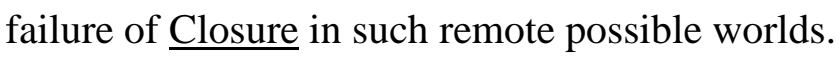

In Kim (2005), Kim argues that NRPs should indeed bother about

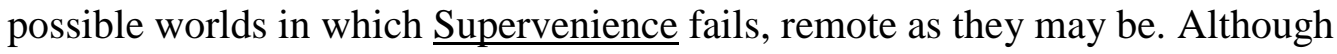


$\underline{\mathrm{W}}$ is nomologically impossible—since some actual laws connecting $\underline{\mathrm{P}}$ and $\underline{\mathrm{M}}$ do not hold-it may very well be a perfect physical duplicate of our world, he says:

[I]n fact, we may stipulate $\mathrm{W}$ to be a perfect duplicate of our world in all physical respects, including spacetime structure, basic physical laws, and fundamental particles. ... [I]t seems obvious to me that anyone who cares

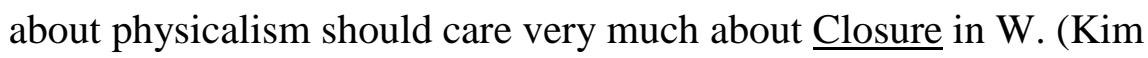
2005, pp. 49-50)

But if $\underline{\mathrm{W}}$ is a perfect duplicate with regard to fundamental particles etc., then how can $\underline{\mathrm{W}}$ neither contain $\underline{\mathrm{P}}$ nor a physical counterpart of $\underline{\mathrm{P}}$ ? In what sense could a world in which $\underline{\mathrm{P}}^{*}$ occurs without having a physical cause really be a perfect physical duplicate with regard to our fundamental physical laws? Apparently, there would have to be a non-physical "influx" of energy, and that would violate our conservation laws. If $\underline{\mathrm{W}}$ is physically possible, although

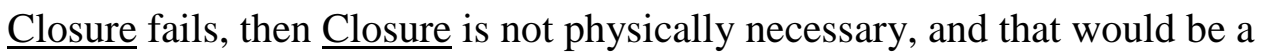
strange claim for a physicalist.

Suppose, however, Kim were right that we can stipulate $\underline{\mathrm{W}}$ to be a perfect physical duplicate of our world. Should NRPs be concerned with the violation

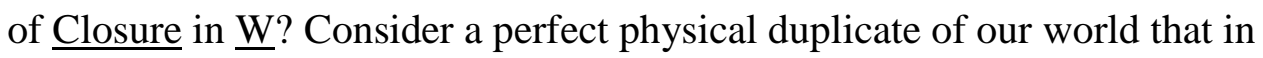
addition to all the physical stuff contains some immaterial mind-stuff that can pass through walls, move faster than the speed of light and do other strange things. If $\underline{\mathrm{W}}$ counts as a physically possible duplicate of our world, so does this 
world, and Closure may fail in it, too (just suppose an immaterial ghost causes the breaking of a window for which there would not have been a sufficient completely physical cause). Should physicalists worry about that? The answer is clearly "No.” In a world with spooky mind-stuff, all bets concerning $\underline{\text { Closure }}$ are off, no matter how physically similar the world is otherwise. Physicalists need not hold, a point forcefully made by Frank Jackson and David Lewis, that physicalism is true in just every world physically exactly like ours. Except for Kim's allegation that "it seems obvious" that physicalists should care very

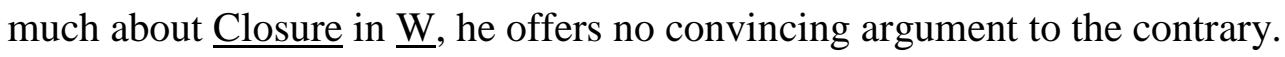
As long as we restrict attention to those worlds pertinent to discussions of

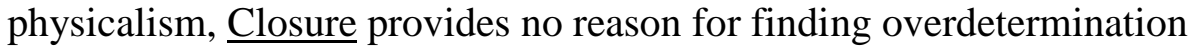
objectionable.

In Kim (2005), Kim offers another argument which is intended to show that the NRPs' invocation of overdetermination does not work even in possible worlds in which Supervenience does hold.

\subsection{Overdetermination and $\underline{\text { Causation }}$}

According to Kim, in a possible world $\underline{\mathrm{W}}$ in which $\underline{\text { Supervenience holds and }}$ both $\underline{\mathrm{M}}$ and its alternative supervenience base $\underline{\mathrm{P}}^{\prime}$ stake a claim at being the cause of an effect $\underline{\mathrm{P}}^{*}, \underline{\mathrm{M}}$ will once again be preempted, this time by $\underline{\mathrm{P}}^{\prime}$ :

Notice, though, that in $\mathrm{W}$, we have a replay of exactly the same situation with which we began- $\mathrm{M}$ has a physical base $\mathrm{P}^{\prime}$, threatening to preempt 
it as a cause of $\mathrm{P}^{*}$... As long as $\underline{\text { Supervenience }}$ is held constant, there is no world in which $\mathrm{M}$ by itself, independently of a physical base, brings about $\mathrm{P}^{*}$; whenever $\mathrm{M}$ claims to be a cause of $\mathrm{P}^{*}$, there is some physical property waiting to claim at least an equal status. (Kim 2005, p. 47)

On one possible reading of this passage, Kim seems to be presupposing the

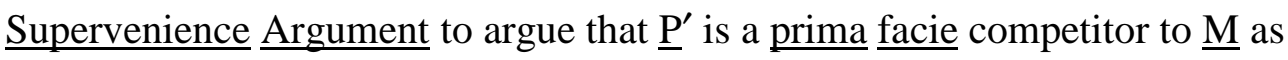
the cause of $\underline{\mathrm{P}}^{*}$. What he seems to be saying, prima vista, is that in $\underline{\mathrm{W}}$, the

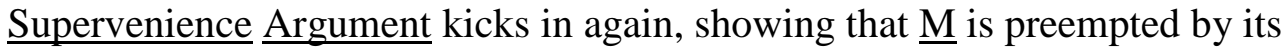
physical supervenience base $\underline{\mathrm{P}}^{\prime}$. However, in order for the Supervenience

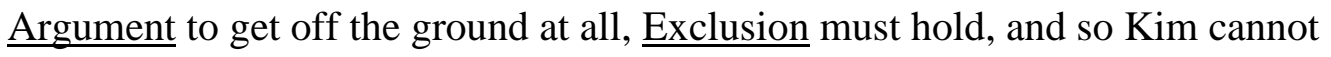

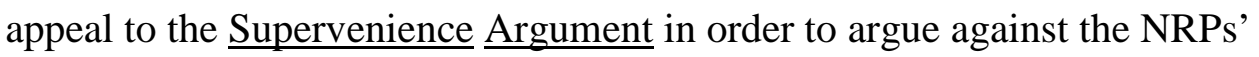
invocation of systematic overdetermination in their attempt to show that Exclusion is false.

There is, however, another reading of this passage. ${ }^{\text {viii }}$ Instead of presenting a straightforward argument for the causal impotence of $\underline{\mathrm{M}}$ in $\underline{\mathrm{W}}$, Kim may simply be challenging NRPs to make intelligible exactly how $\underline{\mathrm{M}}$ could be a cause of $\underline{P}^{*}$. What seems to be bothering Kim is that NRPs cannot offer an adequate account of mental-to-physical causation. He finds the idea that $\underline{\mathrm{M}}$ does, in addition to its physical supervenience base, also act as a cause of $\underline{\mathrm{P}}^{*}$ “totally mysterious":

To be a cause of $\mathrm{P}^{*}, \mathrm{M}$ must somehow ride piggyback on physical causal chains-distinct ones depending on which physical property subserves M 
on a given occasion, in the same world or in other possible worlds. And we may ask: In virtue of what relation it bears to physical property $\mathrm{P}$ does $\mathrm{M}$ earn its entitlement to a free ride on the causal chain from $\mathrm{P}$ to $\mathrm{P}^{*}$ and to claim this causal chain to be its own? Obviously, the only significant relation $\mathrm{M}$ bears to $\mathrm{P}$ is supervenience. But why should supervenience confer this right on $\mathrm{M}$ ? The fact of the matter is that there is only one causal process here, from $\mathrm{P}$ to $\mathrm{P}^{*}$, and M's supposed causal contribution to the production of $\mathrm{P}^{*}$ is totally mysterious. (Kim 2005, p. 48)

According to Kim, NRPs, must explain exactly what it is about $\underline{\mathrm{M}}$ (and its relation to its physical supervenience base $\underline{P}$ ) that renders it suitable as a cause of $\underline{\mathrm{P}}^{*}$, given that mere supervenience, as he points out, does not suffice (thereby rejecting his previous account in Kim [1984b]).

It is probably right to read Kim as claiming that overdetermination ${ }^{\text {ix }}$ is not an option for NRPs because there is no adequate account of causation on which overdetermination would make sense. But, first, why exactly does he think this? And, second, is he entitled to this assumption? Let me first answer the first question, before explaining why I think the answer to the second question ought to be "No."

NRPs are usually quite straightforward about what they think qualifies a supervenient mental property as a cause of a given effect in addition to its physical supervenience base. They have suggested, for instance, that supervenient mental properties make a causal difference in virtue of figuring in 


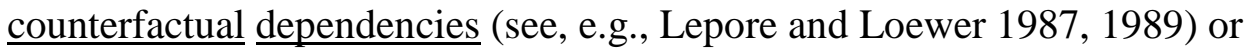
explanations of an appropriate kind (see, e.g., Baker 1993, 1995; Jackson and Pettit 1990), in virtue of being determinables of their physical supervenience bases (see, e.g., Yablo 1992) or in virtue of falling under non-strict causal laws (see, e.g., Fodor 1989; McLaughlin 1989). ${ }^{\mathrm{x}}$ On none of these accounts is overdetermination problematic (there is nothing objectionable per se about the idea that one event counterfactually depends upon two or more events, that one event is explainable [maybe at different levels] by appeal to two or more events, or that there are causal regularities with the same consequent but different antecedents). In fact, these accounts are developed with the explicit goal in mind to make intelligible how a mental property can be causally efficacious in addition to its physical supervenience base. Why, then, does Kim think they are inadequate?

Kim has not been very forthcoming about this issue for years, but recently he has finally admitted that his "thinking about causation and mental causation" (Kim 2002, p. 675) and "the concept of causation underwriting the arguments [i.e., the Supervenience and Exclusion Argument; S.W.]" (Kim forthcoming) “depend on the use of a robust, 'thick' concept of productive or generative causation rather than a 'thin' concept based on the idea of counterfactual dependence or simple Humean "constant conjunctions..." (Kim 2005, p. 38n6). A conception of causation as production or generation is one according to which "causation [is] a relation in which the cause generates or produces the effect" (Loewer 2001, p. 320). According to Kim, such a conception of causation, which is quite congenial to a conserved quantity 
account of causation (i.e., causation as energy flow or momentum transfer; see Fair 1979; Dowe 2000), is the only conception of causation worth considering in the context of mental causation and human agency:

[W]e care about mental causation, it seems to me, chiefly because we care about human agency, and evidently agency involves a productive/generative notion of causation. An agent is someone who brings about a state of affairs for reasons. If there indeed are no productive causal relations in the world, that would effectively take away agency—and our worries about mental causation along with it. (Kim forthcoming)

Kim's commitment to a productive conception of causation explains why he thinks treating an irreducible mental property $\underline{\mathrm{M}}$ as a cause of a physical effect $\underline{\mathrm{P}}^{*}$ is "totally mysterious," given that $\underline{\mathrm{P}}^{*}$ already has a sufficient physical cause: once $\underline{\mathrm{P}}^{*}$ is "generated" or "produced" by one cause, it is "there," so to speak, and it cannot be "generated" or "produced" in any intelligible sense by another cause again, no matter whether the overdetermination would be systematic or not.

I am ... asking the reader to think of causation in terms of actual productive/generative mechanisms involving energy flow, momentum transfer and the like, and not merely in terms of counterfactual dependencies. Needless to say, the overdetermination idea makes little 
$\underline{\text { sense }} \underline{\text { when causation }} \underline{\text { is }} \underline{\text { understood this }}$ way. (Kim 2005, p. 47n12;

emphasis S.W.)

Kim's real difficulty with overdetermination, the one which has apparently motivated his struggle against NRP throughout the past decades and which it has taken him years to state explicitly, has thus little to do with $\underline{\text { Closure, the }}$ coincidental nature of typical cases of genuine overdetermination, or the apparent dispensability of overdetermining causes, and everything with his conviction that it is mandatory to think of mental-to-physical causation in terms of a productive/generative conception of causation. Here, however, a problem lurks. What legitimizes Kim's appeal to his productive/generative conception of causation?

First of all, he offers hardly any positive arguments for why we ought to think of causation (at least of the kind relevant for mental-to-physical causation) in terms of production or generation. ${ }^{\mathrm{xi}}$

Second, as long as non-reductive accounts of mental causation are still in the offing, Kim's claim that it is mandatory to adopt a productive/generative conception of causation will hardly be convincing. ${ }^{\text {xii }}$ If he wants to rule out overdetermination, he must offer an argument for why a productive/generative conception of causation is the only game in town. And in order to do that, he must offer independent arguments for why the non-reductive alternatives are not really an option-he cannot rely on the Supervenience Argument, since the

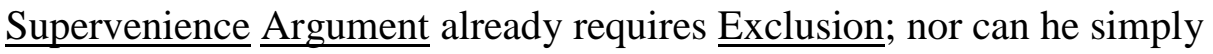
presuppose the superiority of a productive/generative conception of causation. 
As far has I am aware of, Kim has never provided any other independent argument. $^{\text {xiii }}$

As long as Kim does not address this issue properly, his reasons for resisting overdetermination, although perhaps understandable, remain unconvincing, and this undermines his case for reductive physicalism. With the overdetermination option still alive, the Supervenience $\underline{\text { Argument does not }}$ entail "either reduction or causal impotence," but only "either reduction or causal impotence or overdetermination.”xiv

\section{The Generalization Argument}

Some NRPs have argued that the Supervenience Argument cannot be correct since it would not only render irreducible mental properties epiphenomenal but macroproperties tout court (see van Gulick 1992, p. 325; Block 2003). The reasoning is simple enough: What seems to deprive mental properties of their causal status is their relationship to physical properties, viz., supervenience $\underline{\text { without reduction, }}$ and it is not implausible to think that all macroproperties stand in this relationship to the properties below them in the micro-macro-

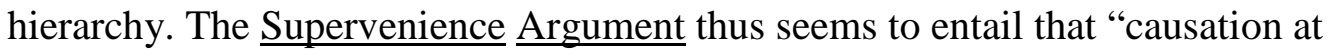
any level gives way to causation at the next lower level" (Kim 2005, p. 52), with the result that causal powers seem to "drain away" all the way down to the fundamental level (if there is such a level; see Schaffer 2003). Kim has employed four different strategies to defend his $\underline{\text { Supervenience }} \underline{\text { Argument }}$ against this alleged reductio. 


\subsection{The Generalization Argument: $\underline{\text { Irreducibility and Exclusion }}$}

Kim's first response is simply to stress that the Supervenience $\underline{\text { Argument has }}$ the form of a reductio. Epiphenomenalism concerning mental properties is the absurdity that allegedly forces us to discard Irreducibility. Hence, says Kim, if the Generalization Argument is correct and the epiphenomenalism in question covers not only mental properties but macroproperties in general, that only adds to its force because it provides "us with one more reason to perform a reductio against the irreducibility premise" (Kim 2005, p. 69).

We can agree with the proponents of the generalization objection that epiphenomenalism is false-not only in regard to mental properties but also [in regard to; S.W.] biological, chemical, geological, and other special science properties. But then one of the premises must be rejected. Which one? A committed physicalist has only one choice: the antireductionist premise. Reductionism wins. So if you are a nonreductive physicalist, you are ill-advised to attack the exclusion/supervenience arguments by deriving further unpalatable consequences. (Kim forthcoming)

From Kim's point of view, the absurdity of epiphenomenalism shows that the $\underline{\text { Irreducibility premise must be rejected, and if the Generalization Argument }}$ shows that the epiphenomenalism in question covers all macroproperties, this 
only makes it more reasonable, for him, to reject Irreducibility.

However, Kim's point cuts both ways, for another crucial premise of the $\underline{\text { Supervenience }} \underline{\text { Argument }}$ is, of course, Exclusion.${ }^{\mathrm{xv}}$ From the point of view of Kim's opponents (at least those who are unwilling to countenance the possibility that mental causation may be a genuine case of overdetermination), it is Exclusion which is reduced to absurdity by the epiphenomenalist conclusion. For them, the fact that the epiphenomenalism in question threatens to cover macroproperties in general also provides us with one more reason to perform the reductio, but this time against $\underline{\text { Exclusion. }}$ Kim and his opponents can agree that $\underline{\text { Irreducibility, }} \underline{\text { Supervenience, }} \underline{\text { Closure, }}$, and Exclusion lead to absurd consequences, and they can agree that the consequences would be even more absurd if they applied to all macroproperties. What they disagree about, however, is whether Irreducibility or Exclusion is the premise that must be discarded in order to avoid the absurdity, and Kim's remarks above provide no reason to think Irreducibility is the only choice for a committed physicalist.

\subsection{The Generalization Argument: $\underline{\text { Levels, }}$ Orders, and $\underline{\text { Supervenience }}$}

Kim's second response draws on a distinction he introduced in Kim (1998) between levels and orders. Very briefly, his idea was the following: Macroproperties fall into two classes-higher-level properties and higher-order properties. The Supervenience $\underline{\text { Argument does not apply to higher-level }}$ properties, he said, because they do not supervene upon lower-level properties, so that the analogue of $\underline{\text { Supervenience fails in this case and stage one does not }}$ 
get off the ground. Moreover, since most higher-order properties can be reduced to lower-order properties, the analogue of Irreducibility fails in this

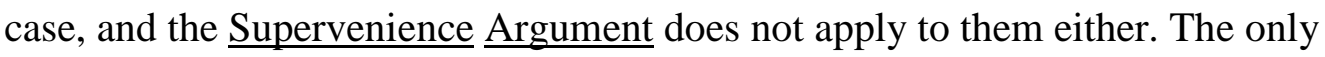
macroproperties threatened by the Supervenience $\underline{\text { Argument are irreducible }}$ higher-order properties, and since except for phenomenal properties of conscious experience (the notorious qualia) there presumably are no only irreducible higher-order properties, the Supervenience Argument does not generalize.

Two issues play an important role here: supervenience (do higher-level properties supervene upon lower-level properties?) and reduction (are higherorder properties reducible to lower-order properties?). This section is concerned with supervenience, section 3.4 with reduction.

The Supervenience Argument, Kim argued in Kim (1998), would apply to higher-level properties only if the subvenient/supervenient distinction mirrors the relation between fundamental and higher-level properties, and this is an assumption he rejects. A property's level depends upon what object it is a property of-properties of objects with parts are higher-level properties, while properties of objects with no parts are fundamental properties. Supervenience, however, generates an intralevel hierarchy of lower- and higher-order properties. Each level contains higher-order properties that supervene upon lower-order properties at the same level, but higher- and lower-level properties are exemplified by different objects, viz., wholes and their parts, respectively. Since supervenience is necessarily a relation between properties of the same objects ("It is evident that a supervenient property and $\underline{\text { its }} \underline{\text { base properties }}$... 
$\underline{\text { are }}$ at the same level on the micro-macro hierarchy; they are properties instantiated by the very same objects and systems"; Kim 1997, p. 291), higherand lower-level properties are thus not related by supervenience. Higher-level properties are non-supervenient, structural or microbased properties objects have in virtue of their mereological structure:

Having a mass of ten kilograms is a property of certain aggregates of molecules, like my coffee table. And it is a micro-based property of the table in the following sense: for my table to have this property is for it to consist of two parts, its top and its pedestal, such that the first has a mass of six kilograms and the second has a mass of four kilograms.... We may say that:

$\underline{\mathrm{P}}$ is a micro-based property just in case $\underline{\mathrm{P}}$ is the property of being completely decomposable into nonoverlapping proper parts, $\underline{\mathrm{a}}_{1}, \underline{\mathrm{a}}_{2}, \ldots, \underline{\mathrm{a}}_{\mathrm{n}}$ such that $\underline{\mathrm{P}}_{1}\left(\underline{\mathrm{a}}_{1}\right), \underline{\mathrm{P}}_{2}\left(\underline{\mathrm{a}}_{2}\right), \ldots, \underline{\mathrm{P}}_{\mathrm{n}}\left(\underline{\mathrm{a}}_{\mathrm{n}}\right)$, and $\underline{\mathrm{R}}\left(\underline{\mathrm{a}}_{1}\right.$, $\left.\ldots, \underline{a}_{n}\right) .(\operatorname{Kim} 1998$, p. 84)

Microbased properties of the form $\underline{\mathrm{R}}\left(\underline{\mathrm{P}}_{1} \underline{\mathrm{O}}_{1}, \ldots, \underline{\mathrm{P}}_{n} \underline{\mathrm{O}}_{n}\right)$ do not supervene upon the properties $\underline{\mathrm{P}}_{1}, \ldots, \underline{\mathrm{P}}_{\mathrm{n}}$, and the relation $\underline{\mathrm{R}}$ that make up their microbase. Therefore, the Supervenience Argument does not apply to them, and there is no drainage of causal powers from level to level:

Micro-based (or microstructural) properties of an object are its macroproperties - they belong to the whole object, not to its 
constituents — and, moreover, they do not supervene on the properties of the object's micro-constituents. For that reason, the supervenience argument does not touch micro-based properties. (Kim 2005, p. 57)

Is it true—as Kim puts it: "evident"—-that supervenience necessarily relates properties of the same object? In an earlier paper, Kim himself characterized a supervenience relation between properties of objects in domains $\underline{D}_{1}$ and $\underline{D}_{2}$ that are coordinated by a mapping relation $\underline{\mathrm{R}}$ such that for each object $\underline{\mathrm{x}}$ in $\underline{\mathrm{D}} 1, \underline{\mathrm{R}} / \underline{\mathrm{x}}$ is the image of $\underline{x}$ in $\underline{D}_{2}($ see Kim 1988, p. 124):

The $\underline{A}$-properties of the objects in $\underline{D}_{1}$ supervene upon the $\underline{B}$-properties of the objects in $\underline{D}_{2}$, relative to relation $\underline{R}$, iff for any objects $\underline{x}$ and $\underline{y}$ in $\underline{D}_{1}$ and any worlds $\underline{w}_{1}$ and $\underline{w}_{2}$, if $\underline{\mathrm{R}} / \underline{\mathrm{x}}$ in $\underline{\mathrm{w}}_{1}$ is $\underline{\mathrm{B}}$-indiscernible from $\underline{\mathrm{R}} / \underline{\mathrm{y}}$ in $\underline{\mathrm{w}}_{2}$, then $\underline{x}$ in $\underline{w}_{1}$ is $\underline{A}$-indiscernible from $\underline{y}$ in $\underline{w}_{2}$.

If $\underline{\mathrm{R}}$ is the identity relation, this is an intralevel notion of strong supervenience, but if $\underline{\mathrm{R}}$ is the part/whole relation, it is an interlevel notion of mereological supervenience between the properties of wholes and the properties of their parts. Given such a notion of supervenience, the Supervenience Argument would equally well apply to microbased properties, so that they, too, would be preempted by the properties in their microbase.

One response would be to restrict the Supervenience Argument to properties which supervene upon properties of the same objects and simply to disregard mereologically supervenient properties. Yet, this would be ad $\underline{\text { hoc, }}$, in 
particular since the driving idea behind the Supervenience $\underline{\text { Argument is }}$ precisely that only property-identities can avoid Exclusion, and mereologically supervenient properties and their supervenience bases are definitely not identical.

A more plausible move is to ignore the issue of whether supervenience necessarily relates properties of the same object and to argue instead that the $\underline{\text { Supervenience }} \underline{\text { Argument concerns only supervenient properties with no causal }}$ powers of their own. This response is suggested by Kim's repeated insistence that microbased properties enjoy their own causal powers that go beyond those of the properties and relations in their microbase:

This table has a mass of ten kilograms, and this property ... represents a well-defined set of causal powers. But no micro-constituent of this table, none of its proper parts, has this property or the causal powers it represents. $\mathrm{H}_{2} \mathrm{O}$ molecules have causal powers that no oxygen or

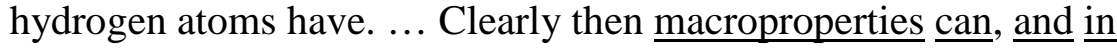
general do, have their own causal powers, powers that go beyond the causal powers of their microconstituents. (Kim 1998, p. 85)

Since this response squares nicely with what Kim has to say about microbased properties and their causal powers at other places in $\operatorname{Kim}(1998,2005)$, let us see whether construing microbased properties as properties with a proprietary set of causal powers renders them immune to the Supervenience Argument. 


\subsection{The Generalization Argument: Determination and Causal Powers}

What, to begin with, is it that allegedly prevents a microbased property $\underline{\mathrm{P}}$ from being preempted by other properties? $\underline{\mathrm{P}}$ can, of course, not be preempted by a structural property of the form $\underline{\mathrm{R}}\left(\underline{\mathrm{P}}_{1} \underline{\mathrm{O}}_{1}, \ldots, \underline{\mathrm{P}}_{n} \underline{\mathrm{O}}_{n}\right)$, because it is $\underline{\text { identical to that }}$ property: "[Micro-based properties; S.W.] do not supervene on [their constituent properties; S.W.] individually or as a group. Rather, they supervene on specific mereological configurations involving these microproperties-for a rather obvious and uninteresting reason: they are identical with these microconfigurations" (Kim 1998, pp. 117-118). ${ }^{\mathrm{xvi}}$

But what prevents $\underline{\mathrm{P}}$ from being preempted by the (appropriately related) individual properties $\underline{P}_{1}, \ldots, \underline{P}_{n}$ that make up its microbase? After all, the idea behind the Supervenience Argument is that supervenient properties are fully determined by the properties in their supervenience base that seem to do all the causal work. Likewise, microbased properties seem to be fully determined by the individual properties in their microbase. Why do we not have to conclude that all the causal work is done solely by the latter, leaving nothing to do for microbased properties?

Kim's answer seems to be that microbased properties are not, appearances to the contrary, determined by the properties in their microbase:

[S] upervenience is ... a relation of determination, but micro-basing is not. If $\underline{\mathrm{P}}$ is the property of being made up of parts, $\underline{\mathrm{x}}_{1}, \ldots, \underline{\mathrm{x}}_{\mathrm{n}}$ such that $\underline{\mathrm{P}}_{1}\left(\underline{\mathrm{x}}_{1}\right), \ldots, \underline{\mathrm{P}}_{\mathrm{n}}\left(\underline{\mathrm{x}}_{\mathrm{n}}\right)$ and $\underline{\mathrm{R}}\left(\underline{\mathrm{x}}_{1}, \ldots, \underline{\mathrm{x}}_{\mathrm{n}}\right) \ldots[\mathrm{w}] \mathrm{e}$ clearly cannot think of $\underline{\mathrm{P}}_{1}, \ldots$ 
$\underline{\mathrm{P}}_{\mathrm{n}}$, and $\underline{\mathrm{R}}$ taken together as determining $\underline{\mathrm{P}}$. For to say that the properties 'determine' $\underline{P}$, in the usual sense, is to say (at least) that necessarily any object that has them has $\underline{\mathrm{P}}$. But this condition is at best vacuous in the present case: an object that has $\underline{\mathrm{P}}$ cannot be expected to have any of the $\underline{P}_{i} s$ or $\underline{R}$. The reason of course is that the $\underline{P}_{i} s$ are the properties of the object's proper parts, and $\underline{\mathrm{R}}$ is a relation, not a property. (Kim 1999, p. 117)

Hence, microbased properties fail to be determined by the (appropriately related ${ }^{\mathrm{xvii}}$ properties in their microbase for the same reason they allegedly fail to supervene upon them: they are exemplified by distinct objects.

Just as in the case of supervenience, however, the question is why a notion of determination which restricts determination to properties of the same object is the correct notion to adopt. There seems to be a straightforward and intuitive sense of "determines" according to which microbased properties are determined by the properties in their microbase: the table's having a mass of ten kilograms seems to be determined by its consisting of a six kilo top and a four kilo pedestal. Such a notion of determination, according to which a's having $\underline{\mathrm{F}}$ (or $\underline{\mathrm{a}}_{1}, \ldots, \underline{\mathrm{a}}_{\mathrm{n}}$ 's having $\underline{\mathrm{F}}_{1}, \ldots, \underline{\mathrm{F}}_{\mathrm{n}}$, respectively) determines $\underline{\mathrm{b}}$ 's having $\underline{\mathrm{G}}$ just in case necessarily, whenever $\underline{\mathrm{a}}$ is $\underline{\mathrm{F}}\left(\right.$ or $\underline{\mathrm{a}}_{1}, \ldots, \underline{\mathrm{a}}_{\mathrm{n}}$ are $\underline{\mathrm{F}}_{1}, \ldots, \underline{\mathrm{F}}_{\mathrm{n}}$, respectively) $\underline{b}$ is $\underline{G}$, contrasts sharply with Kim's notion of determination according to which $\underline{F}$ determines $\underline{G}$ just in case necessarily any object that has $\underline{F}$ has $\underline{G}$, and is intuitively certainly no less legitimate. ${ }^{x i i i}$ The burden of proof, it seems, is with anyone who denies the viability of such a notion of 
determination.

Fortunately, one need not quarrel over the right notion of determination. If one accepts Kim's reasoning in other places, it seems hard to deny that microbased properties are preempted by the properties in their microbase. When criticizing non-reductive accounts of mental causation, Kim questions the causal status of mental properties vis-à-vis physical effects by asking, what, given the sufficient physical causes guaranteed by $\underline{\text { Closure, }}$ "causal work is left over for [the] mental property to do?" (Kim 1993a, 354; he raises similar questions in Kim 1990, 45; 1993b, 361; 1998, 37). Similarly, no matter whether microbased properties are determined by the properties in their microbase or not, what causal work is there left over for them to do, given that the properties in their microbase suffice to bring about any effect they may be said to have? Once the properties $\underline{P}_{1}, \ldots, \underline{P}_{n}$ in the microbase of a property $\underline{P}$ are instantiated, everything is done, causally speaking, so that there is nothing left for the complex $\underline{\mathrm{R}}\left(\underline{\mathrm{P}}_{1} \underline{\mathrm{O}}_{1}, \ldots, \underline{\mathrm{P}}_{\mathrm{n}} \underline{\mathrm{n}}_{\mathrm{n}}\right)$, and thus for the microbased property $\underline{\mathrm{P}}$ to which it is identical, to do. That seems to entail the all-encompassing epiphenomenalism concerning higher-level (microbased) properties that Kim wants to avoid.

One may legitimately ask why once the properties $\underline{P}_{1}, \ldots, \underline{P}_{n}$ in $\underline{P}$ 's microbase are instantiated, everything is done, causally speaking. Kim himself, although he denies that a microbased property $\underline{\mathrm{P}}$ is determined by the properties $\underline{\mathrm{P}}_{1}, \ldots, \underline{\mathrm{P}}_{\mathrm{n}}$ in its microbase, explicitly admits that the "causal powers of $\ldots \underline{\mathrm{P}}$ may be fixed, or determined, by the causal powers of the properties and relations, $\underline{\mathrm{P}}_{1}, \ldots, \underline{\mathrm{P}}_{2}, \underline{\mathrm{R}}$, that figure in $\underline{\mathrm{P}}$ 's construction as a micro-based 
property" (Kim 1998, pp. 116-117). Is the fact that the causal powers of $\underline{\mathrm{P}}$ are fixed or determined by the causal powers of $\underline{P}_{1}, \ldots, \underline{P}_{n}$ not already enough reason to think that once $\underline{\mathrm{P}}_{1}, \ldots, \underline{\mathrm{P}}_{\mathrm{n}}$ are there, and properly arranged, all the causal work is done? Not according to Kim. In Kim (2005) he insists that the fact that the causal powers of microbased properties are fixed by the causal powers of the properties in their microbase does not lead to a generalization of the Supervenience Argument:

Considerations like those motivating the supervenience argument do not have eliminative implications for macrocausation in general; the supervenience argument does not eliminate all macrocausation ... This baseball has causal powers that none of its proper parts, in particular none of its constituent microparticles, have, and in virtue of its mass and hardness, the baseball can break a window ... Presumably, the causal powers of the baseball are determined by its microstructural features and perhaps also explainable in terms of them. But determination and or explanation need have no eliminative implications. Perhaps, macrocausal relations are constituted by, or composed of, a bunch of microcausal relations. But that does not banish macrocausation out of existence ... All this is consistent with the supervenience argument. (Kim 2005, p. 56)

However, how can the Supervenience Argument be consistent with instances of macrocausation that are due to the fact that the causal powers of macroobjects are determined by the causal powers of their microstructural 
features, if Edwards' dictum, according to which vertical determination excludes horizontal causation, is the driving idea behind the Supervenience Argument (see section 1.1)? How can it be compatible with the baseball's figuring in horizontal causal relations, if the baseball's causal powers are vertically determined by the causal powers of its microconstituents, and the $\underline{\text { Supervenience }}$ Argument is motivated by Edwards' dictum?

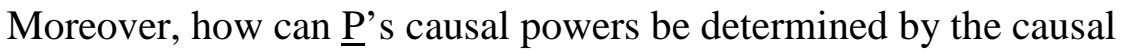

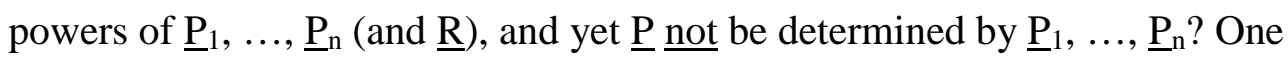
would think that all that is required for $\underline{\mathrm{P}}$ to be determined by $\underline{\mathrm{P}}_{1}, \ldots, \underline{\mathrm{P}}_{\mathrm{n}}$ is that its causal powers be determined by the causal powers of $\underline{P}_{1}, \ldots, \underline{P}_{n}($ and $\underline{R})$. What else could be needed?

Finally, if $\underline{\mathrm{P}}$ 's causal powers are determined by the causal powers of $\underline{\mathrm{P}}_{1}$, $\ldots, \underline{\mathrm{P}}_{2}$ (and $\underline{\mathrm{R}}$ ), does that not exactly mean, pace Kim, that there is no causal work left over for $\underline{\mathrm{P}}$ do to- once the causal potential of an object is fixed by $\underline{\mathrm{P}}_{1}$, $\ldots, \underline{\mathrm{P}}_{2}$ (and $\underline{\mathrm{R}}$ ), what contribution could $\underline{\mathrm{P}}$ make? Once those properties of a table which (appropriately related) make up the microbase of its property of having a mass of ten kilograms (among other things) are present, then the table's causal potential is fixed, and there is nothing left for the table's having a mass of ten kilograms to contribute (no matter whether that property is determined by the properties in its microbase or not). ${ }^{\text {xix }}$

It seems that Kim's last bastion against an all-encompassing higher-level epiphenomenalism is the claim we first encountered at the end of section 3.2, viz., the claim that microbased properties can, and in general do, have their own proprietary set of causal powers that go beyond the causal powers of the 
properties in their microbase (although the latter may determine the former). Undoubtedly, there is a sense in which wholes have causal powers none of their parts have - a table, for instance, may have the causal powers to make a scale read "10 kg," causal powers arguably none of its proper parts have, and a baseball may have the causal powers to break a window, causal powers none of its parts may have. ${ }^{\mathrm{xx}}$ But does that sense really secure the causal efficacy of the wholes vis-à-vis their parts, especially given that their causal powers are still fixed, or determined, by the causal powers of their parts? Of course, Jack and Jill, as a pair, have causal powers none of them individually has—say, lifting a stone so heavy that neither of them can lift it alone. But as long as their causal powers as a pair are fixed by their causal powers as individuals—as long as it is true that as soon as Jack and Jill, as individuals, have the causal powers they have, they, as a pair, have the causal powers they have-there is nothing that

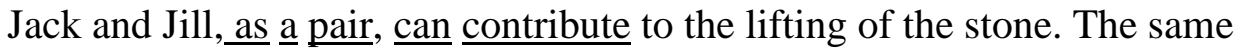
seems to hold for microbased properties and the properties in their microbase: Of course, the former enjoy causal powers the latter do not have, but as long as the former's causal powers are fixed by the latter's causal powers-as long as it is true that as soon as the latter have the causal powers they have, the former have the causal powers they have-there is nothing that the former can contribute to the production of, say, a scale's reading " $10 \mathrm{~kg}$ " or a window's breaking.

Even if Kim's various remarks about determination, microbasing, and the determination of causal powers could be combined into a coherent wholeapparently not an easy task, as this section has shown-they do not seem to be 
sufficient to prevent the driving idea behind the Supervenience $\underline{\text { Argument from }}$ generalizing to higher-level properties tout court.

\subsection{The Generalization Argument: Reduction}

Recall that there is still one more issue left to be addressed. Section 3.2 said that according to Kim, there is no universal interlevel drainage of causal powers because higher-level properties fail to supervene upon the properties in their micro-bases, a claim which eventually gave rise to the discussion in section 3.3. However, the possibility of an intralevel causal drainage, where the higher-order properties at each level are preempted by the first-order properties of that level, was also raised, and discussion of it was postponed until this section.

Since the upshot of the Supervenience Argument is "either reduction or causal impotence," intralevel causal drainage requires that higher-order properties be irreducible, and according to Kim, that is usually not the case. The appeal to the reducibility of higher-order macroproperties is still Kim's "primary response to the drainage argument" (Kim 2005, p. 69). The basic idea is simple—where there is only one property, there can be no competition, and where there is no competition, there can be no exclusion: "Reduction is the stopper that will plug the cosmic hole through which causal powers might drain away" (Kim 2005, p. 68).

But how are the reductions in question to be accomplished? Higher-order properties, Kim said in Kim (1998), are reducible if they are susceptible to 
functional reductions according to which the property to be reduced is first analyzed in terms of its causal role, then the physical property that plays that causal role within a world, species, or structure is sought, and finally the property to be reduced is (locally) identified with that physical role-filler (see Kim 1998, pp. 98-99). Since most higher-order properties seem to be characterizable in terms of their causal role, and thus susceptible to functional reductions, each level contains (except for a few non-functionalizable exceptions like phenomenal properties) strictly speaking only first-order properties, and this apparently dissolves the problem of universal intralevel causal drainage.

In Kim (2005), Kim still defends the functional account of reduction (see Kim 2005, p. 101), but he seems to have abandoned the explicit distinction between orders and levels, arguing that reduction is also the key to stopping interlevel causal drainage:

Let us say that the property of being $\mathrm{H}_{2} \mathrm{O}$ is the total micro-based property of water at the atomic level $\mathrm{L}$ (so having $\mathrm{M}_{\mathrm{L}}=$ being $\mathrm{H}_{2} \mathrm{O}$ ). So we have:

(1) Being water $=$ having $\mathrm{M}_{\mathrm{L}}$.

At the next level down, L-1, say the level of the Standard Model, hydrogen atoms have a certain microstructural composition as do oxygen atoms, and water has a certain microstructural composition at this level; 
call it $\mathrm{M}_{\mathrm{L}-1}$. Then by the same reasoning that led us to (1), we have:

(2) Being water $=$ having $\mathrm{M}_{\mathrm{L}-1}$.

At the level L-2, the one below the Standard Model (if there is such a level), water is again going to have a certain microstructure at this level; this is $\mathrm{M}_{\mathrm{L}-2}$. We then have:

(3) Being water $=$ having $\mathrm{M}_{\mathrm{L}-2}$.

And so on down the line, to $\mathrm{M}_{\mathrm{L}-3}$ and the rest. These identities in turn imply the following series of identities:

$$
\mathrm{M}_{\mathrm{L}}=\mathrm{M}_{\mathrm{L}-1}=\mathrm{M}_{\mathrm{L}-2}=\mathrm{M}_{\mathrm{L}-3} \ldots
$$

Voilà! These are the identities we need to stop the drainage. (Kim 2005, pp. 68-69)

Let us first consider Kim's recent suggestion that reductions, or identities, can also secure the causal status of higher-level (microbased) properties, before returning to his original idea that they can secure the causal status of higherorder properties.

$\underline{\text { Reduction }} \underline{\text { and microbased properties }}$ 
As various authors have pointed out, one problem with Kim's attempt to block causal drainage by appeal to identities is that microbased properties seem to have "multiple compositions" (see Block 2003, p. 146; Loewer 2001, 2002; Schröder 2002, p. 324). Kim says the table's having a mass of ten kilograms is the microstructural property of being composed of two appropriately related parts, a six kilo top and a four kilo pedestal, but it seems that the table could have the same property in virtue of being composed of a five kilo top and a five kilo pedestal. The property of being $\mathrm{H}_{2} \mathrm{O}$ also seems to have multiple compositions: "Being a water molecule is not an aggregate or conjunction of fundamental microphysical properties but a vast disjunction, since water molecules can occupy infinitely many quantum states" (Loewer 2001, p. 316n3). Multiple composability raises two problems. First, if microbased properties are multiply composable or realizable, the multiple realizability of mental properties does not seem to prevent them from being microbased properties in Kim's sense. Second, and maybe more importantly, the series of identities Kim appeals to in order to stop causal drainage would seem to be impossible: "Micro-based properties are supposed to prevent draining away ..., but Kim's plugging the draining with micro-based properties depends on assuming identities (such as 'water $=\mathrm{H}_{2} \mathrm{O}$ ') and multiple composition will exclude such identities" (Block 2003, p. 146).

In response, Kim insists that multiple composability does not preclude the identification of higher-level properties and their microbases: 
First, in spite of jade's multiple composition, each instance of jade ... is either jadeite or nephrite, and I don't see anything wrong about identifying $\underline{\text { its }}$ being jade with $\underline{\text { its }}$ being nephrite (if it is nephrite) or with its being jadeite (if it's jadeite).... All we need is identity at the level of instances, not necessarily at the level of kinds and properties; causation after all is a relation between property or kind-instances, not between properties or kinds as such. ... [Second, we can; S.W.] ... identify jade with a disjunctive kind, jadeite or nephrite (that is, being jade is identified with having the microstructure of jadeite or the microstructure of nephrite).... On the disjunctive approach, being jade turns out to be a causally heterogeneous property, not a causally inert one. ... To disarm Block's multiple composition argument, adopting either disjunctive property/kind identities or instance (or token) identities seems sufficient. $(\operatorname{Kim} 2005$, p. 58-59)

First, however, if token-identities can secure the causal efficacy of jade, despite its multiple composability, then why can they not secure the causal efficacy of irreducible mental properties, despite their multiple realizability? After all, NRPs can allow that Sarah's being in pain at $\underline{t}_{1}$ is (identical to) her being in brain state $\underline{s}_{1}$ at $\underline{t}_{1}$, while Sarah's being in pain at $\underline{t}_{2}$ is (identical to) her being in brain state $\underline{\mathrm{s}}_{2}$ at $\underline{\mathrm{t}}_{2}$. If Kim is right that "[a]ll we need is identity at the level of instances, not necessarily at the level of kinds and properties," then where is the problem for NRP? ${ }^{\mathrm{xxi}}$ Second, one wonders why Kim thinks he could have identities of instances without identities at the level of types. After all, for him 
property-instances are events, whose identity conditions entail that the instances are identical only if the types are identical (see note 1). ${ }^{\text {xii }}$

Concerning the second option, suppose that being jade is identical to a disjunction of two microstructural properties. Given what Kim says elsewhere, the causal powers of the individual properties in the two microbases that form the disjunction determine the causal powers of being jade (and being jade is definitely not identical to these properties). Hence, ascribing these properties to an object exhaustively fixes its causal potential, so that nothing is left for being jade to do, even though it is identical to a disjunction of two microstructural properties. That point should be familiar from the discussion in section 3.3: The identity of a microbased property $\underline{\mathrm{P}}$ with the structural property $\underline{\mathrm{R}}\left(\underline{\mathrm{P}}_{1}, \ldots\right.$, $\left.\underline{P}_{n}\right)$, although it prevents $\underline{P}$ from being preempted by $\underline{R}\left(\underline{P}_{1}, \ldots, \underline{P}_{n}\right)$, does not prevent $\underline{\mathrm{P}}$ from being preempted by $\underline{\mathrm{P}}_{1}, \ldots, \underline{\mathrm{P}}_{\mathrm{n}}$. Likewise, although being jade cannot be preempted by the disjunction of the two microstructural properties to which it is identical, it can still be preempted by the individual disjuncts.

Could multiply composable microbased properties perhaps be functionally reduced? After all, functional reductions are compatible with multiple realizability, because they show that "when realization is properly understood, multiple realization only leads to reducibility to multiple reduction bases, not to irreducibility" (Kim 2005, p. 56). However, functional reductions are a non-starter for microbased properties, because they are eliminative:

The trouble is that the treatment of micro-based properties cannot be at all similar to the functionalist reduction of higher-order properties. There, 
we found that the elimination of multiply realized properties was alleviated by 'local reductions': e.g., of temperature-in-gases to MTKE [mean translational kinetic energy; S.W.]. But if we eliminate multiply micro-based properties, there will be no similar compensation, for MTKE cannot be locally reduced. That is, there is no way to reduce MTKE-inneon to one micro-configuration or MTKE-in-freon to another, for there

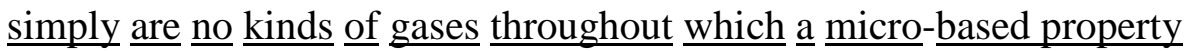
$\underline{\text { like }} \underline{\text { MTKE }} \underline{\text { can }}$ be correlated one-to-one with a specific configuration of microproperties. (Bontly 2002, pp. 87-88)

The causal efficacy of multiply composable microbased properties can therefore neither be vindicated by disjunctive identities, nor by token-identities, nor by functional reductions. Functional reductions are eliminative and thus a bad choice for microbased properties; instance-identities may allow for a reduction of multiply composable microbased properties, but also for a reduction of multiply realizable mental properties as NRPs conceive of them, and that is something Kim cannot accept; and disjunctive identities (just like identities between microbased properties and structural properties) do not seem to be able to prevent preemption. It seems, therefore, that Kim's most recent attempt to secure the causal status of higher-level properties, fails.

\section{$\underline{\text { Reduction and higher-order properties }}$}

What about Kim's original suggestion that functional reductions can secure the 
causal efficacy of higher-order properties? As said above, functional reductions are eliminative. A functionally reduced property $\underline{\mathrm{F}}$ has to be given up as a genuine property which can be exemplified in different species, and we retain only the predicate " $\underline{x}$ has $\underline{F}$ " and the concept $\underline{F}$ by which we equivocally pick out different properties in different species (see Kim 1998, p. 106). It is thus a red herring to think that functional reductions can vindicate the causal efficacy of the properties reduced, because these properties get sundered into many different species- or structure-specific properties during the process of reduction. It is these structure-specific properties that are identical to first-order properties. Hence, even assuming that interlevel causal drainage could somehow be stopped, they, i.e., the first-order properties at each level, would be the only causally efficacious properties. If this is the only kind of causally efficacious property that the proponent of the Supervenience $\underline{\text { Argument can }}$ protect from her own argument (and again: even that much would require stopping the problem of interlevel causal drainage first), her position will hardly look attractive—and definitely not like "a plausible terminus for the mind-body debate" (Kim 2005, p. 173), given that properties like thinking,

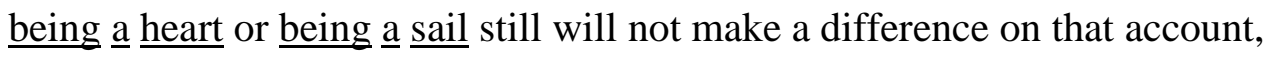
since functional reductions can vindicate at best the causal efficacy of thinking-

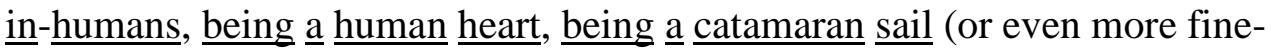
grained properties).

\section{4. $\quad$ Conclusion}


All in all, it seems that Kim has not (yet) provided a coherent metaphysical overall picture of the mind and its place in the physical world. First, without any convincing argument for his productive/generative account of causation, which can only be given by means of a careful rejection of alternative nonreductive accounts on a case by case basis that Kim does not provide, his

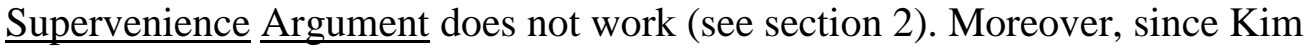
has no convincing reply to the Generalization Argument, NRPs will consider the consequence of an all-encompassing macroepiphenomenalism as a reductio of what they take to be the weakest premise in the Supervenience Argument, viz., Exclusion. Finally, as long as Kim cannot give a successful response to the Generalization Argument, he cannot both appeal to the Supervenience Argument in order to show that NRP cannot account for the causal efficacy of irreducible mental properties, and at the same time insist that his own reductionist approach can preserve the causal efficacy of (most) mental properties and of all other macroproperties (section 3).

Certainly no one with a serious interest in the metaphysics of mind can afford addressing Kim's challenges or ignoring his position, and the questions and concerns raised above may provide only the starting point for further discussion and criticism, but pace Kim, the position he defends in Physicalism, Or Something Near Enough is not "a plausible terminus for the mind-body debate."

\section{Acknowledgements}

An early predecessor of this paper was written in 2004 while I was a visiting 
fellow at the department of philosophy at the Ohio State University, thanks to a DAAD grant. Support from both institutions is gratefully acknowledged. I would like to thank three anonymous referees for Philosophical Psychology for various valuable comments and suggestions.

\section{Notes}

${ }^{i}$ Like Jaegwon Kim I will think of events as property-exemplifications (so that mental events cannot be physical events unless mental properties are physical properties), and like Kim I will speak of properties as causes, although strictly speaking it is events, i.e. instances of properties, that are causes.

ii This is the formulation in Kim (forthcoming). A more formal characterization of (strong) supervenience would be: A set of properties $\Sigma$ strongly supervenes upon a set of properties B iff necessarily, for any property $\underline{\mathrm{S}} \in \Sigma$, an object $\underline{\mathrm{O}}$ has $\underline{S}$ at $\underline{t}$ only if there is a property $\underline{B} \in \mathrm{B}$ such that $\underline{\mathrm{o}}$ has $\underline{\mathrm{B}}$ at $\underline{\mathrm{t}}$ and necessarily, if any object $\underline{o}^{\prime}$ has $\underline{B}$ at $\underline{\mathrm{t}}, \underline{\mathrm{o}}^{\prime}$ has $\underline{\mathrm{S}}$ at $\underline{\mathrm{t}}$ (see Kim 1984a, p. 65). iii The exact modal force of this sufficiency claim depends upon the modal force of the second necessity operator in the definition of strong supervenience (see note ii).

iv Kim's invocation of Edwards' dictum is particularly striking in the light of the fact that he has little to offer to bolster it, except for some illustrative examples (see Kim 2005, pp. 36-38).

${ }^{\mathrm{v}}$ In fact, it seems, he does not do so- -he mentions it, but it is not explicitly used as a premise (Kim 2005, pp. 39-40). Kim thus spends several pages on a 
barely motivated, intuitively not very plausible and very strong principle which, in the end, he does not put to use (thanks to an anonymous referee here).

${ }^{\text {vi }}$ This is what Kim calls "Completion 2" of stage two (Kim 2005, pp. 44-45). "Completion 1" (Kim 2005, pp. 41-44) holds that $\underline{\mathrm{M}}$ must supervene upon a physical property $\underline{\mathrm{P}}$ which has at least as good a claim for being $\underline{\mathrm{P}}^{*}$ 's cause as $\underline{M}$, thereby creating the causal competition between $\underline{M}$ and $\underline{P}$ that eventually

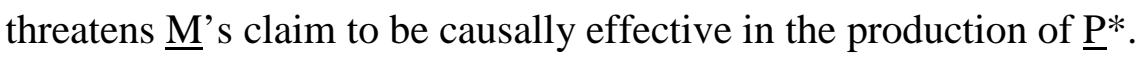
${ }^{\text {vii }}$ Assuming, again, that genuine overdetermination is not an option. viii Thanks to an anonymous referee for suggesting this reading of Kim and to two other anonymous referees for prompting me to clarify Kim's assumptions about the nature of causation and to elaborate on the possibility of providing a positive account of causation that permits the kind of overdetermination NRP requires.

ix I will drop the qualifier "systematic" from now on.

${ }^{\mathrm{x}}$ Note that some of these accounts do not ground the causal efficacy of a mental property in a relation its bears to its supervenience base, but in a relation it bears to the effect. Note also that Yablo does not claim that being a determinable renders a mental property causally efficacious; he only claims that it prevents it from being preempted by its physical determinates.

${ }^{x i}$ Kim does not say a word about how he thinks of causation in Kim (1998), and even though the issue came to the fore in a discussion with Barry Loewer in 2002 (see Loewer 2001, 2002; Kim 2002), in Kim (2005) he still relegates 
his discussion of causation to the two footnotes cited above, without offering any substantial argument in favor of a productive/generative conception of causation. Even in Kim (forthcoming), where he finally acknowledges the crucial role his conception of causation plays in his arguments (see also Walter 2006), he says little in its defense (except for claiming that without it genuine agency would be impossible; see above, p. 000).

xii Mostly because in contrast to Kim's account of causation, the non-reductive alternatives can make sense of the idea that irreducible mental properties do have a role to play in the causal course of the (physical) world.

xiii In Kim (2005, pp. 48-49) he invites "anyone tempted by the idea that mental events make their causal contributions by being overdetermining causes [to] reflect on whether this option could sufficiently vindicate the causal efficacy of the mental," but he does not offer any positive reason for why nonreductive accounts of mental-to-physical causation are inadequate. Of course, he may very well be right that these accounts are too weak to do justice to our intuitions concerning mental causation, but this cannot simply be taken for granted, it must be shown, on a case by case basis, for every nonreductive account of mental causation (see Walter 2006 for a more detailed presentation of this argument), and this is exactly what Kim has desisted so far.

xiv This is not to say that overdetermination is altogether unproblematic and Kim's argument of no use whatsoever. He does draw attention to the fact that anyone who appeals to overdetermination owes us an account of exactly what it is that makes an overdetermining cause a cause properly so called. But 
conversely, anyone who finds overdetermination unattractive must say something substantial about why it is inadequate, without presupposing the

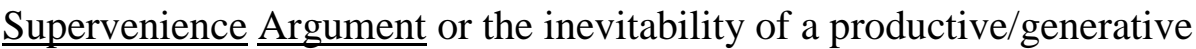
account of causation. See Walter (2005) for an argument against Jackson and Pettit's attempt to ground the causal efficacy of the mental in its ability to figure in so-called "program explanations," Walter (2007a) for an argument against Baker's attempt to ground the causal efficacy of the mental in its explanatory status, and Walter (2007b) for an argument against Yablo's appeal to the determinable/determinate distinction in the attempt to prevent a preemption of the mental by the physical.

${ }^{x v}$ In Kim's presentation of the Supervenience Argument in Kim (2005), Exclusion is invoked in lines (8) and (9) of Completion 2 of stage two (see $\operatorname{Kim} 2005$, p. 44).

${ }^{x v i}$ Noordhof (1999, p. 112) argues that microbased properties can be preempted by their microbases, but as Kim (1999, pp. 116-117) points out correctly, no characterization he ever gave of microbased properties allows them to be separated from their microbases in such a way (Schröder 2002 also seems to commit Noordhof's mistake).

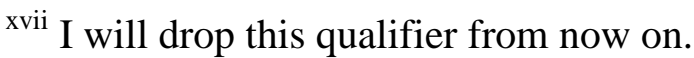

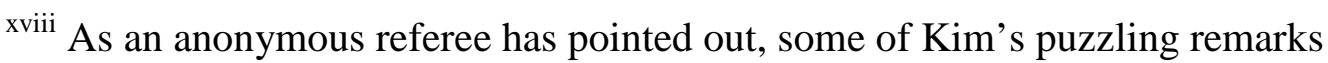
concerning levels, orders, determination, and causal powers discussed in this section can best be understood as a consequence of his using "determines" in a more artificial, stipulated sense that does not match the usual intuitive idea. 
${ }^{x i x}$ To be sure: The question what causal work is left over for $\underline{P}$ to do, given the sufficiency of the structural property $\underline{\mathrm{R}}\left(\underline{\mathrm{P}}_{1} \underline{\mathrm{O}}_{1}, \ldots, \underline{\mathrm{P}}_{\mathrm{O}} \underline{\mathrm{O}}_{\mathrm{n}}\right)$ is misguided, since $\underline{\mathrm{P}}$ just is $\underline{\mathrm{R}}\left(\underline{\mathrm{P}}_{1} \underline{\mathrm{o}}_{1}, \ldots, \underline{\mathrm{P}}_{\mathrm{n}} \underline{\mathrm{O}}_{n}\right)$. Yet, the question what causal work is left over for $\underline{\mathrm{P}}$ to do, given the sufficiency of the causal powers of $\underline{P}_{1}, \ldots, \underline{P}_{n}($ and $\underline{R})$ is an entirely different and perfectly legitimate question.

${ }^{x x}$ Assuming the window can just withstand the impact of anything less heavy/less hard than the baseball.

${ }^{x x i}$ An anonymous referee has pointed out that since Kim is not at all bothered by multiple realizability (see Kim 1992b), he would say that mental properties would all be reducible via instance-identifications, if multiple realizability were the only problem, but that what makes mental properties irreducible is something else, viz., the notorious problems associated with qualia. It is of course true that, for Kim, it is the peculiar qualitative character of (phenomenal) mental properties, and not their multiple realizability, that renders a functional analysis solely in terms of their causal role and thus a reduction impossible. That, however, or so NRPs can maintain without palpable incoherence, concerns properties as types, not properties as tokens: the peculiar qualitative character of (phenomenal) mental properties shows that phenomenal properties, as types, they cannot be reduced to physical types, but it is compatible with their reducibility, as tokens, to physical tokens (see, for instance, the discussion about the "old fact/new guise" response to Frank Jackson's famous Knowledge Argument). 


\section{References}

Baker, L. (1993). Metaphysics and mental causation. In J. Heil and A. Mele (Eds.), Mental Causation (pp. 75-95). Clarendon Press, Oxford.

Baker, L. (1995). Explaining Attitudes. Cambridge University Press, Cambridge.

Block, N. (2003). Do causal powers drain away? Philosophy and Phenomenological Research 67 , 133-150.

Bontly, T. (2002). The supervenience argument generalizes. Philosophical $\underline{\text { Studies }} \underline{109}, 75-96$.

Crisp, T.M. and Warfield, T.A. (2001) Kim's master argument (Review of

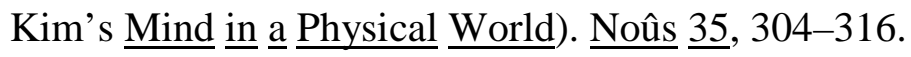

Dowe, P. (2000). Physical Causation. Cambridge University Press, Cambridge.

Fair, D. (1979). Causation and the flow of energy. Erkenntnis 14, 219-250.

Fodor, J. (1989). Making mind matter more. Philosophical Topics 17, 59-79.

Jackson, F. and Pettit, P. (1990). Program explanation: A general perspective. $\underline{\text { Analysis }}$ 50, 107-117.

Kim, J. (1984a). Concepts of supervenience. Philosophy and $\underline{\text { Phenomenological Research }} \underline{45}, 153-176$. Reprinted in Supervenience and Mind: Selected Philosophical Essays (pp. 53-78). Cambridge University Press, Cambridge 1993.

Kim, J. (1984b). Supervenience and supervenient causation. Southern Journal of Philosophy $\underline{22}, 45-56$. 
Kim, J. (1988). Supervenience for multiple domains. Philosophical Topics $\underline{16}$, 129-150. Reprinted in Supervenience and Mind: Selected Philosophical Essays (pp. 109-130). Cambridge University Press, Cambridge 1993. Kim, J. (1989a). The myth of nonreductive materialism. Proceedings of the $\underline{\text { American Philosophical Association }} \underline{63}, 31-47$. Reprinted in

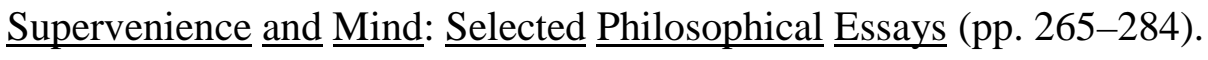
Cambridge University Press, Cambridge 1993.

Kim, J. (1989b). Mechanism, purpose, and explanatory exclusion.

$\underline{\text { Philosophical Perspectives }} \underline{3}, 77-108$. Reprinted in $\underline{\text { Supervenience and }}$ Mind: Selected Philosophical Essays (pp. 237-264). Cambridge University Press, Cambridge 1993.

Kim, J. (1990). Explanatory exclusion and the problem of mental causation. In E. Villanueva (Ed.), Information, Semantics and Epistemology (pp. 3656). Blackwell, Oxford.

Kim, J. (1992a). Downward causation, emergentism and nonreductive physicalism. In A. Beckermann, H. Flohr and J. Kim (Eds.), Emergence or Reduction? Essays on the Prospects of Nonreductive Physicalism (pp. 119-138). De Gruyter, Berlin, New York.

Kim, J. (1992b). Multiple realization and the metaphysics of reduction. Philosophy and Phenomenological Research 52, 1-26.

Kim, J. (1993a). The nonreductivist's troubles with mental causation. In J. Heil and A. Mele (Eds.), Mental Causation (pp. 189-210). Clarendon Press, 
Oxford. Reprinted in Supervenience and Mind: Selected Philosophical

Essays (pp. 336-358). Cambridge University Press, Cambridge 1993.

Kim, J. (1993b). Postscripts on mental causation. In Supervenience and Mind:

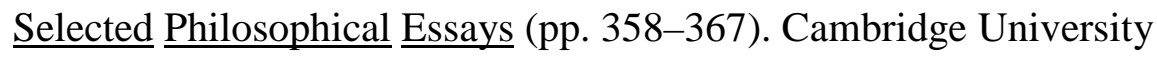

Press, Cambridge.

Kim, J. (1997). Does the problem of mental causation generalize? Proceedings

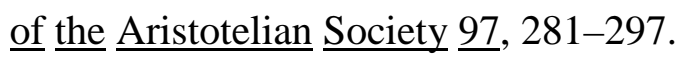

Kim, J. (1998). Mind in a Physical World: An Essay on the Mind-Body

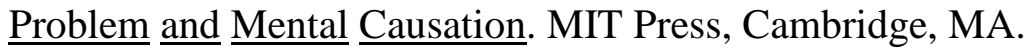

Kim, J. (1999). Supervenient properties and micro-based properties: A reply to

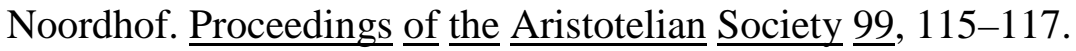

Kim, J. (2001). Mental causation and consciousness: The two mind-body problems for the physicalist. In C. Gillett and B. Loewer (Eds.),

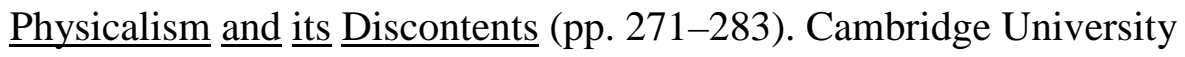
Press, Cambridge.

Kim, J. (2002). Responses. Philosophy and Phenomenological Research $\underline{65}$, $671-680$.

Kim, J. (2003). Blocking causal drainage and other maintenance chores with mental causation. Philosophy and Phenomenological Research $\underline{67}, 151-$ 176.

Kim, J. (2005). Physicalism, Or Something Near Enough. Princeton University Press, Princeton, NJ. 
Kim, J. (forthcoming). Mental causation. In B. McLaughlin, A. Beckermann and S. Walter (Eds.), The Oxford Handbook for the Philosophy of Mind. Oxford University Press, Oxford.

Lepore, E. and Loewer, B. (1987). Mind matters. Journal of Philosophy $\underline{84}$, 630-642.

Lepore, E. and Loewer, B. (1989). More on making mind matter. Philosophical $\underline{\text { Topics }} \underline{19}, 175-191$.

Loewer, B. (2001). Review of Kim's Mind in a $\underline{\text { Physical World. Journal of }}$ Philosophy 98, 315-324.

Loewer, B. (2002). Comments on Jaegwon Kim's Mind in a Physical World. Philosophy and Phenomenological Research 65, 655-662.

McLaughlin, B. (1989). Type epiphenomenalism, type dualism, and the causal priority of the physical. Philosophical Perspectives $\underline{3}$, 109-135.

Noordhof, P. (1999). Micro-based properties and the supervenience argument: A response to Kim. Proceedings of the Aristotelian Society 99, 109-114.

Schaffer, J. (2003). Is there a fundamental level? Nous 37, 498-517.

Schröder, J. (2002). The supervenience argument and the generalization

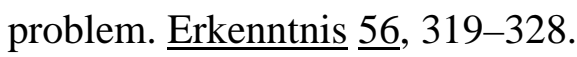

Van Gulick, R. (1992). Three bad arguments for intentional property epiphenomenalism. Erkenntnis $\underline{36}, 311-332$.

Walter, S. (2005). Program explanations and mental causation. Acta Analytica $\underline{20}, 32-47$. 
Walter, S. (2006). Causal exclusion as an argument against non-reductive physicalism. Journal of Consciousness $\underline{\text { Studies }} \underline{13}, 67-83$.

Walter, S. (2007a). The epistemological approach to mental causation. Erkenntnis $67,273-287$.

Walter, S. (2007b). Determinables, determinates, and causal relevance. Canadian Journal of Philosophy $\underline{37}$, 217-244.

Walter, S. (2008). Review of Jaegwon Kim, Physicalism, Or Something Near Enough. European Journal of Philosophy.

Yablo, S. (1992). Mental causation. Philosophical Review 101, 245-280.

xxii Thanks again to an anonymous referee. 